\title{
The Application of Ultrasound During Brain Surgery
}

\author{
William F. Chandler, M.D., and Jonathan M. Rubin, M.D. \\ Section of Neurosurgery and Department of Radiology, University of Michigan Medical Center, Ann Arbor, Michigan, U.S.A.
}

\begin{abstract}
The use of intraoperative, real-time ultrasound imaging during intracranial neurosurgical procedures is described. This technique has proven to be extremely useful for localization of a wide variety of deep and superficial brain lesions, and for needle biopsy or aspiration of selected lesions. The precise localization provided by ultrasonic imaging shortens the time of surgery and increases the safety for the patient.

Every type of primary and metastatic tumor of the brain has imaged well, and low-grade gliomas are often better defined with ultrasound than by computed tomographic scanning. Abscesses can be imaged and aspirated, and hematomas are easily imaged. A variety of vascular lesions including aneurysms and arteriovenous malformations can be localized and characterized. Structural abnormalities such as hydrocephalus and Arnold-Chiari malformation can be well delineated.
\end{abstract}

Attempts have been made since 1951 to apply ultrasound technology to the localization of intracranial lesions during neurosurgical procedures [1]. These early trials performed on the dural surface provided only a linear estimate of the depth of highly echogenic structures, without any imaging capability. With the advent of real-time sector ultrasound scanning in the late 1970's, it was demonstrated that the brain of an infant could be imaged in considerable detail through the open anterior fontanelle [2]. With this imaging capability the next logical step was to attempt to image pathologic structures within the brain during neurosurgical procedures. In $1980 \mathrm{we}$, as well as several others [3-7], demonstrated that a variety of pathologic lesions as well as many normal structures of the brain could be imaged by placing the ultrasound transducer in a sterile covering directly on the brain or dural surface. Since that time, we have learned during several hundred neurosurgical procedures that intraoperative ultrasound imaging is extraordinarily useful to the operating surgeon and provides an additional measure of safety to the patient.

\section{Equipment and Technique}

All ultrasound imaging at our institution has been performed using the equipment of Advanced Technology Laboratories (Bothel, Washington, U.S.A.), but other suitable equipment is available. Having a scanhead containing different frequency

Reprint requests: William F. Chandler, M.D., Taubman Health Care Center 2124/0338, 1500 E. Medical Center Drive, Ann Arbor, Michigan 48109 , U.S.A. transducers is helpful, in that often it is advantageous to image a lesion at various frequencies. Cerebral, cerebellar, and brainstem lesions are generally best imaged with a $5-$ or $3-\mathrm{MHz}$ transducer, but occasionally a 7.5- $\mathrm{MHz}$ transducer is used for very superificial lesions. Imaging is accomplished with equal clarity either through the dura or directly on the brain surface. Because of a near-field artifact that is common to all transducers, it is occasionally beneficial to use a saline "stand-off" for small lesions very near the brain surface. A surgical glove filled with saline functions well and will be demonstrated below. In the posterior fossa and cervical-medullary junction region, the patient may be placed prone and the wound filled with saline to provide the stand-off. Because ultrasound is inherently safe, it can be used as long and as frequently as necessary during the surgery to assist the surgeon. Because it provides immediate and accurate localization it, in fact, usually shortens the operative time.

Real-time ultrasound transducers can easily differentiate solid or necrotic tumors from cystic areas, in fact, better than either computed tomography (CT) or magnetic resonance imaging. Because the image is generated in real-time, pulsating structures as small as the middle cerebral artery can be imaged and the movements observed. Because flowing blood is of low echogenicity, the interior of an aneurysm or large vascular channels in arteriovenous malformations can be differentiated from surrounding structures as relatively hypoechoic areas. Because intraoperative ultrasound provides imaging of normal structures adjacent to various lesions, the relationship to these normal structures can be appreciated before, during, and after resection of a lesion.

Although the principal function of intraoperative ultrasound is localization and characterization of lesions, it also provides a precise means of placing a needle within a lesion for biopsy or aspiration. An accurate and reliable needle guide is commercially available (Advanced Technology Laboratories, Bothel, Washington, U.S.A.) and keeps the biopsy needle within the plane of the ultrasound image. The depth of the desired guide is then preset such that the exact point will be reached. The approach of the needle, the aspiration, and the post-needle removal is all monitored in real-time so that if the lesion is pushed aside by the needle or if bleeding occurs, this can be easily recognized. Virtually any region of the cerebrum, cere- 

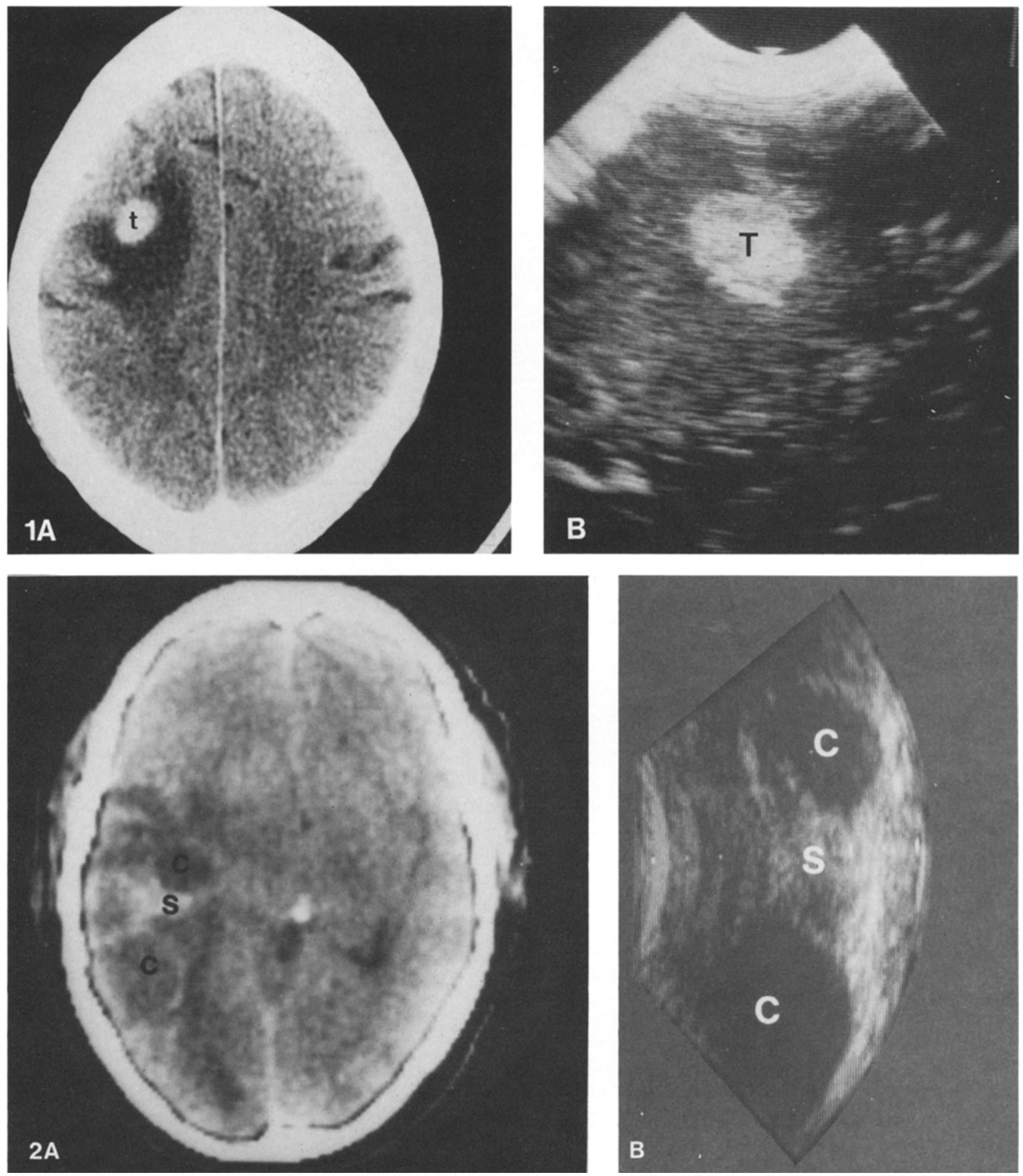

Fig. 1A. Computed tomographic (CT) scan of solitary left frontoparietal metastasis ( $t$ ). B. Ultrasound image of same (T)

Fig. 2A. CT scan of cystic metastasis. B. Intraoperative ultrasound image of the lesion. $\mathrm{S}=$ solid portion, $\mathrm{c}=\mathrm{cystic}$ portions.

bellum, or brainstem can be accurately biopsied with this technique.

With few exceptions, we have used intraoperative ultrasound via a craniotomy rather than a trephine. Although imaging through a trephine is adequate, it does not allow room for simultaneous passage of the biopsy needle.

\section{Examples and Discussion}

Almost every type of intracranial neoplasm has been readily imaged with intraoperative ultrasound, as well as a variety of vascular, infectious, and congenital lesions [8, 9]. Examples of specific entities will be given below, as well as the particular 

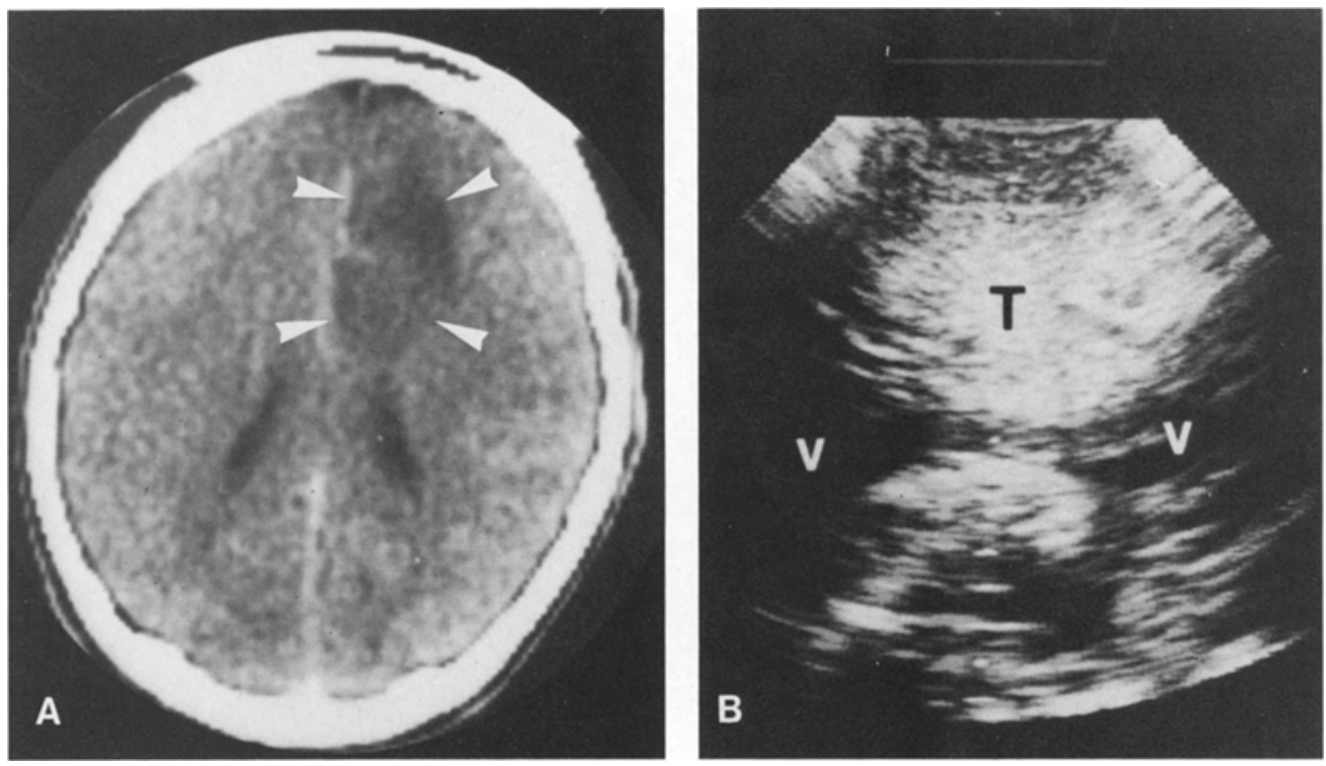

Fig. 3A. CT scan of a grade II astrocytoma (between arrowheads). B. Ultrasound image of same tumor (T) and lateral ventricles (v). Note that tumor is hypodense on CT, but hyperechoic on ultrasound

advantage of ultrasound imaging to each entity. It should be kept in mind that the ability to "look around" in real-time during a procedure is difficult to capture in still photographs.

\section{Tumors}

Metastatic Tumors. Prior to using intraoperative ultrasound imaging, the task of locating a small, solitary, subcortical metastasis was both frustrating and dangerous. With ultrasound imaging, lesions of virtually any size and location can be quickly localized and the safest route of excision planned. Figure 1 demonstrates the preoperative $\mathrm{CT}$ and intraoperative ultrasound images of a small, left-sided, subcortical metastasis. With this precise localization, an overlying sulcus was separated and the tumor removed through a $10-\mathrm{mm}$ incision at the base of the sulcus. Completeness of tumor removal can also be confirmed with ultrasound imaging. To assist in the removal of deeper lesions, a probe may be guided ultrasonically to the tumor and the probe tract followed for excision.

Figure 2 is an example of a cystic metastasis and the ultrasound image clearly demonstrates the solid and cystic portions of the tumor. This information allows the surgeon to proceed directly to the solid portion of the tumor for biopsy and resection.

Low-Grade Gliomas. Localizing slow-growing, low-grade, infiltrating gliomas during surgery can likewise be difficult and inexact. Even though there may be a sizable and obvious abnormality on CT scanning, the tumor may appear very much like a normal brain by gross inspection and even on frozen section pathological examination. We have found, in every instance during intraoperative ultrasound imaging, that these low-grade tumors have an increased echogenicity relative to the surrounding normal brain. This has allowed both identification of the tumor and a much better definition of its borders. Figure 3 is an example of how a low-grade glioma (astrocytoma grade
II) appears as low density on CT but is highly echogenic with ultrasound. Often times portions of a tumor unsuspected on CT scanning, such as extention across the corpus callosum, are identified with ultrasound. Figure 4 demonstrates the solid portion of a low-grade glioma that was not appreciated on CT scanning even with contrast enhancement.

If only a biopsy is appropriate, this can be accomplished using the needle guide; or if excision is indicated, then the extent of the resection can be evaluated. Figure 5 illustrates that a small low-grade astrocytoma in the cerebellum is readily localized with ultrasound. This lesion was totally resected.

High-Grade Gliomas. Although large, high-grade, malignant gliomas are generally not difficult to locate during surgery, intraoperative ultrasound imaging may be helpful to define the borders of a lesion or to provide a safe means of biopsying a deep tumor. Figure 6 shows a well-localized deep glioblastoma with a cystic center. Ultrasound has proven more accurate than CT scanning in differentiating cysts from necrosis, since necrotic material is more echogenic. Cysts are of low echogenicity regardless of protein content.

Figure 7 demonstrates the ability to perform an accurate needle biopsy of a deep glioma. The needle tract remains echogenic because of the disruption of normal tissue, and this can be observed for post-biopsy hemorrhage. Figure 8 demonstrates a malignant glioma of the cerebellum.

Other Tumors. A variety of tumors other than low- or highgrade astrocytomas have been accurately localized and defined by intraoperative ultrasound. There has been no tumor yet, either intrinsic or extrinsic to the brain, that has failed to image with ultrasound. It is useful to image meningiomas which are located deep on the falx, at the base of the skull, within the ventricular system, or to simply image a convexity meningioma to help plan the dural opening. Small posterior fossa tumors such as hemangioblastomas, dermoids, epidermoids, or even 

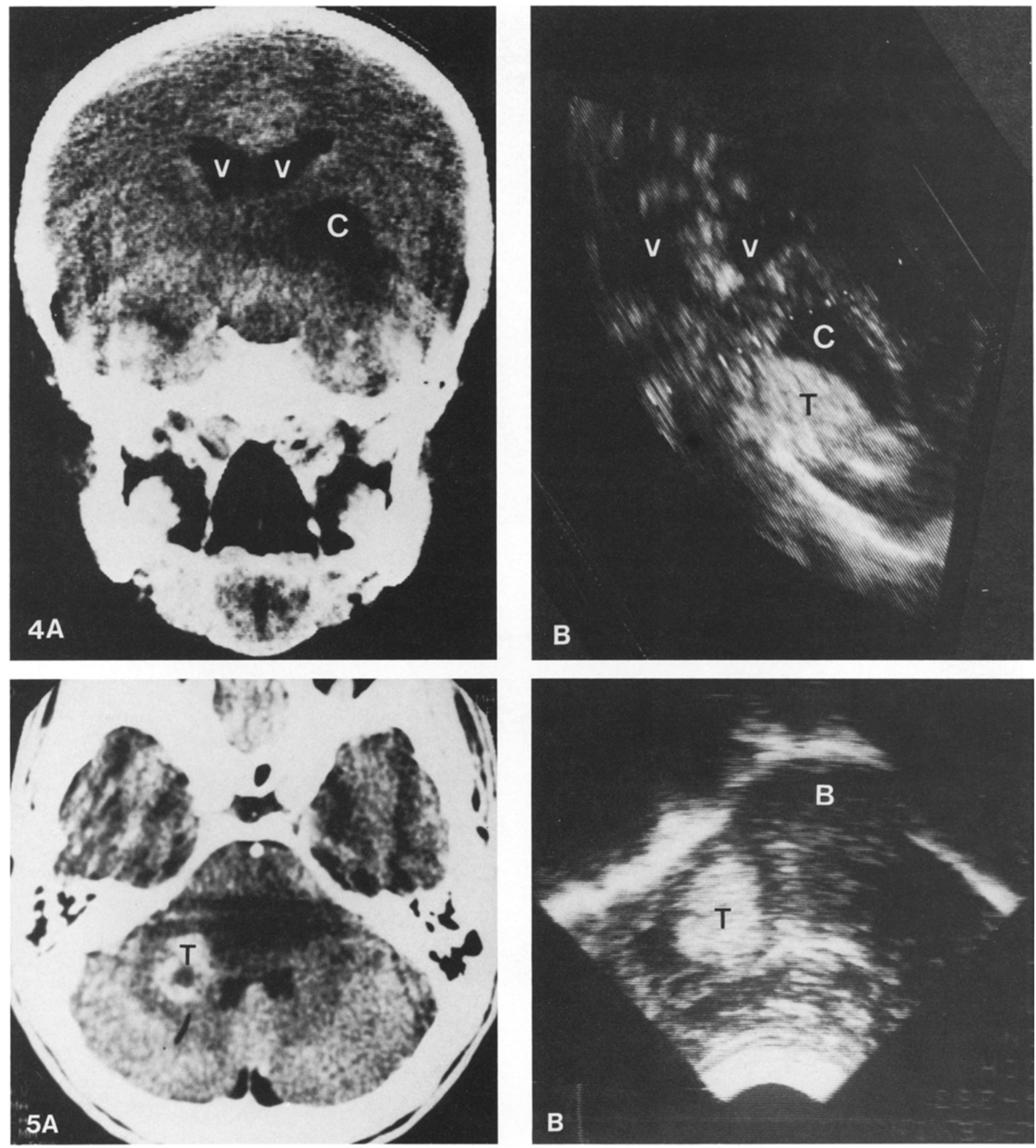

Fig. 4A. Coronal $\mathrm{CT}$ scan with contrast demonstrating a cystic lesion $(\mathrm{C})$ in the right basal ganglion region. B. Ultrasound image demonstrates a solid portion of the tumor (T) that was not appreciated on $\mathrm{CT} . \mathrm{V}=$ ventricles.

Fig. 5A. CT scan of small grade II astrocytoma of cerebellum (T). B. Ultrasound image shows the hyperechoic tumor (T) and the typically hypoechoic brainstem (B). 

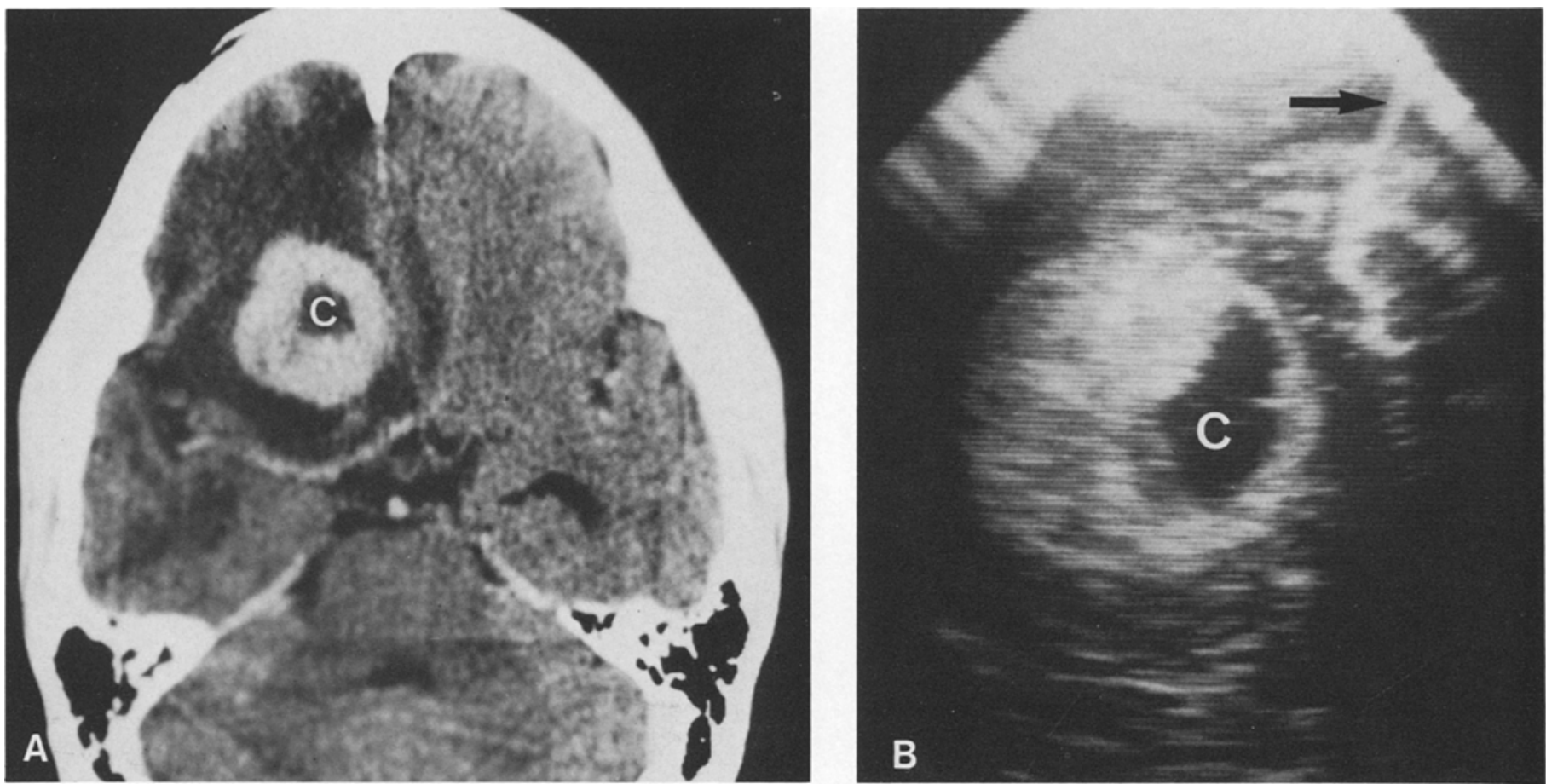

Fig. 6A. CT scan of left frontal glioblastoma with cystic center (C). B. Ultrasound image of tumor with cystic center (C). The falx is to the upper right of the tumor (arrow).
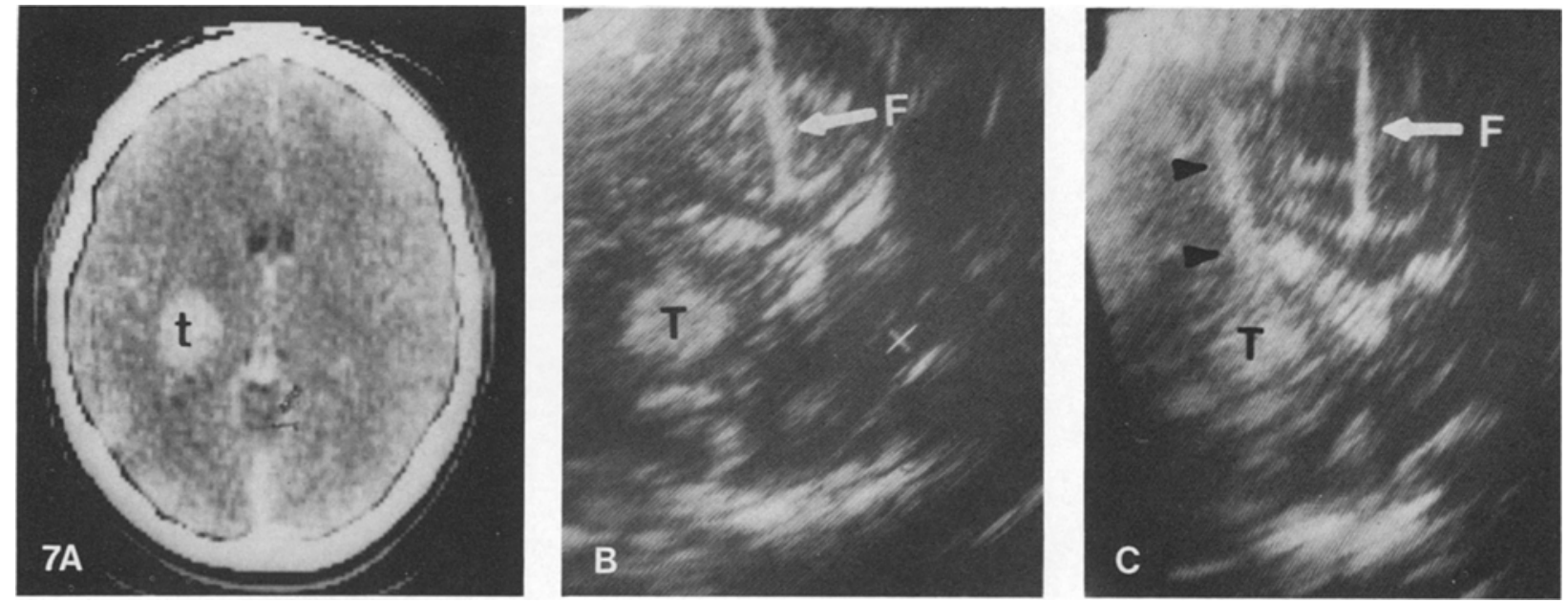

Fig. 7A. CT scan of deep left high-grade astrocytoma (t). B. Ultrasound image of the tumor (T) and the falx (F). C. Ultrasound image after needle biopsy showing the needle tract (arrowheads).

common ependymomas and medulloblastomas can be easily visualized with ultrasound and the relationship to the fourth ventricle defined. We have also visualized lymphomas, germinomas, neuromas, and gangliogliomas. Figure 9 demonstrates a deep left paraventricular ganglioglioma. The ultrasound image shows the relationship of the tumor to the lateral ventricle and to the falx. Figure 10 is from a young man with a pineal region germinoma. This was approached via the posterior fossa and the ultrasound image demonstrates its relationship with the pineal gland, the choroid plexus, and the tentorium.

\section{Infectious Lesions}

Abscesses of varying sizes and consistency as well as cerebritis have been visualized well with ultrasound. Depending on the stage of development of the abscess, the center may be of low, medium, or high echogenicity. Accurate intraoperative localization allows safe needle aspiration and immediate assessment of the residual abscess cavity. In many deep abscesses the aspiration plus antibiotics may be the only therapy needed. Figure 11 is a subcortical abscess with associated cerebritis 

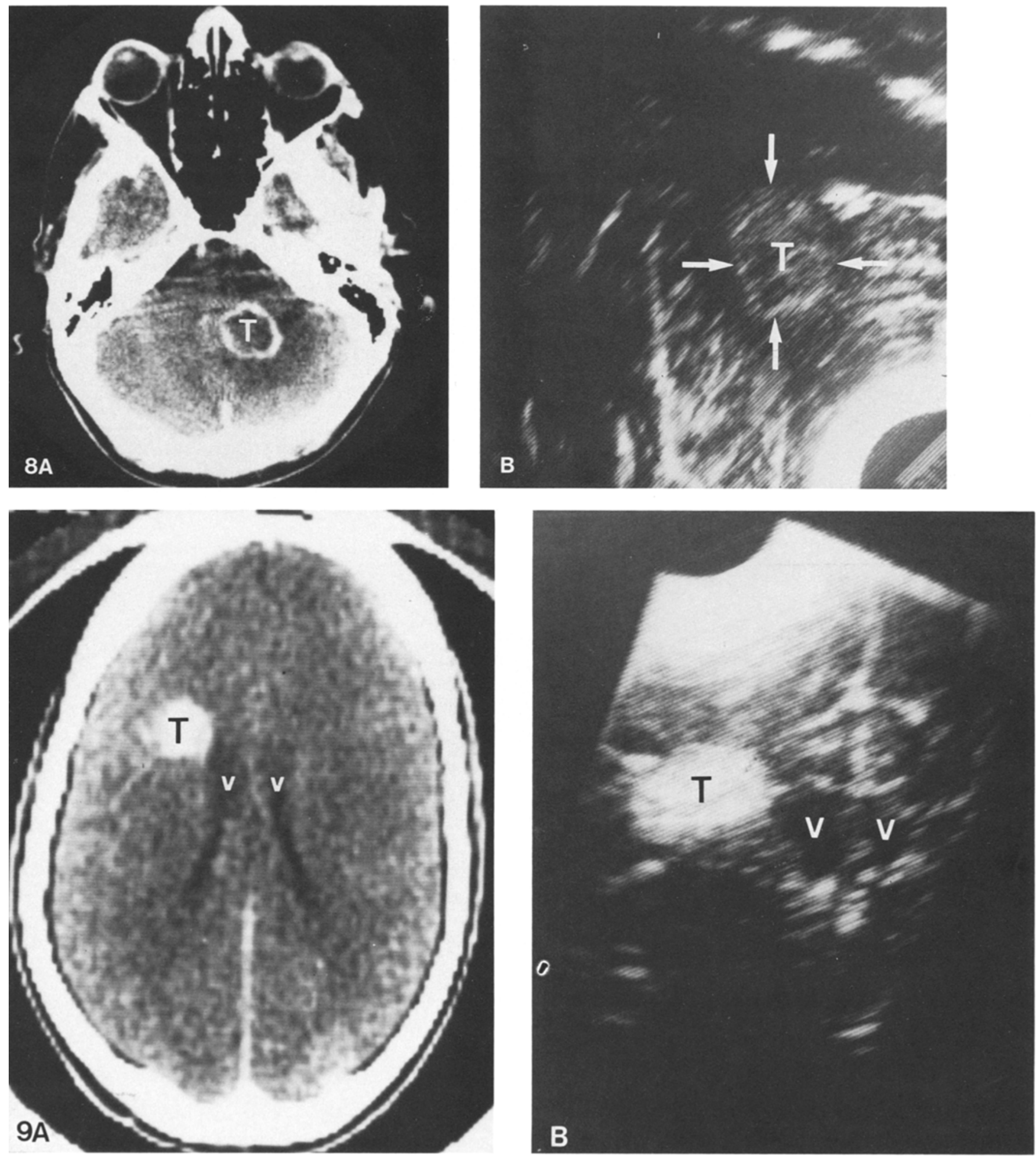

Fig. 8A. CT scan of necrotic high-grade glioma of cerebellum (T). B. Ultrasound image of tumor (T; between arrows).

Fig. 9A. CT scan of left paraventricular ganglioglioma. B. Ultrasound of tumor and ventricles. $T=$ tumor, $v=v e n t r i c l e$. 

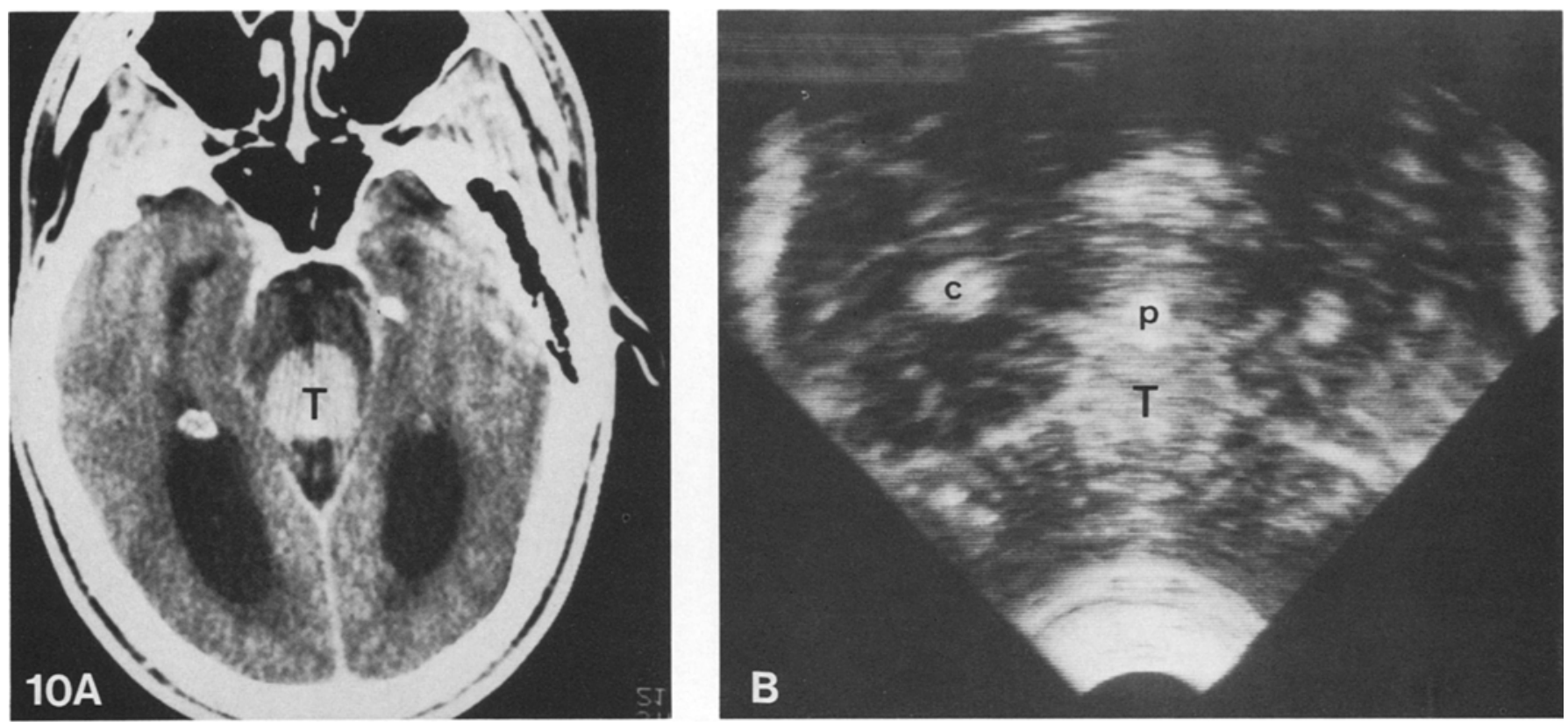

Fig. 10A. CT scan of pineal region germinoma (T). B. Ultrasound image via the posterior fossa of the tumor (T) as well as the pineal gland (p) and the glomus of the choroid plexus (c).
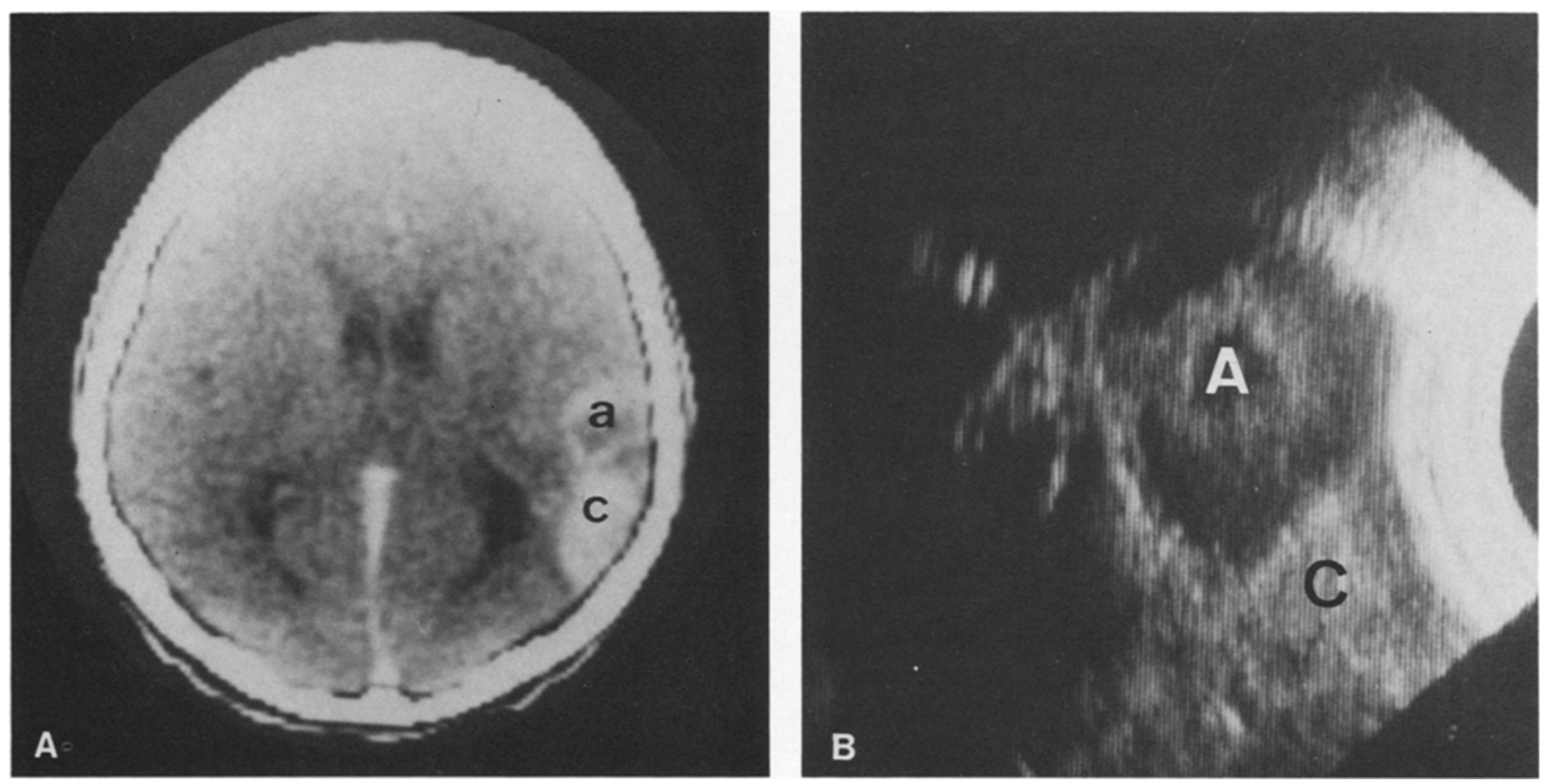

Fig. 11A. CT scan of abscess (a) with associated cerebritis (c). B. Ultrasound image of abscess (A) and cerebritis (C).

imaged via a craniotomy. On one occasion we have aspirated a large deep abscess via a trephine under local anesthesia by first imaging the abscess and determining the depth and direction of the desired aspiration, then passing a needle free-hand into the abscess.

Cerebritis is seen as tissue with increased echogenicity relative to the normal brain. We have observed this in association with bacterial abscesses and in 1 case of Brucillosis of the temporal lobe.

\section{Vascular Lesions}

A variety of vascular lesions have been imaged, including active and thrombosed arteriovenous malformations (AVM's) and several aneurysms. Active AVM's image as a mixture of high and low echogenicity (Fig. 12). Since flowing blood is hypoechogenic relative to surrounding brain, the large feeding and draining vessels as well as portions of the lesion itself are hypoechogenic. The multiple interfaces formed by the conglomerate mass of 

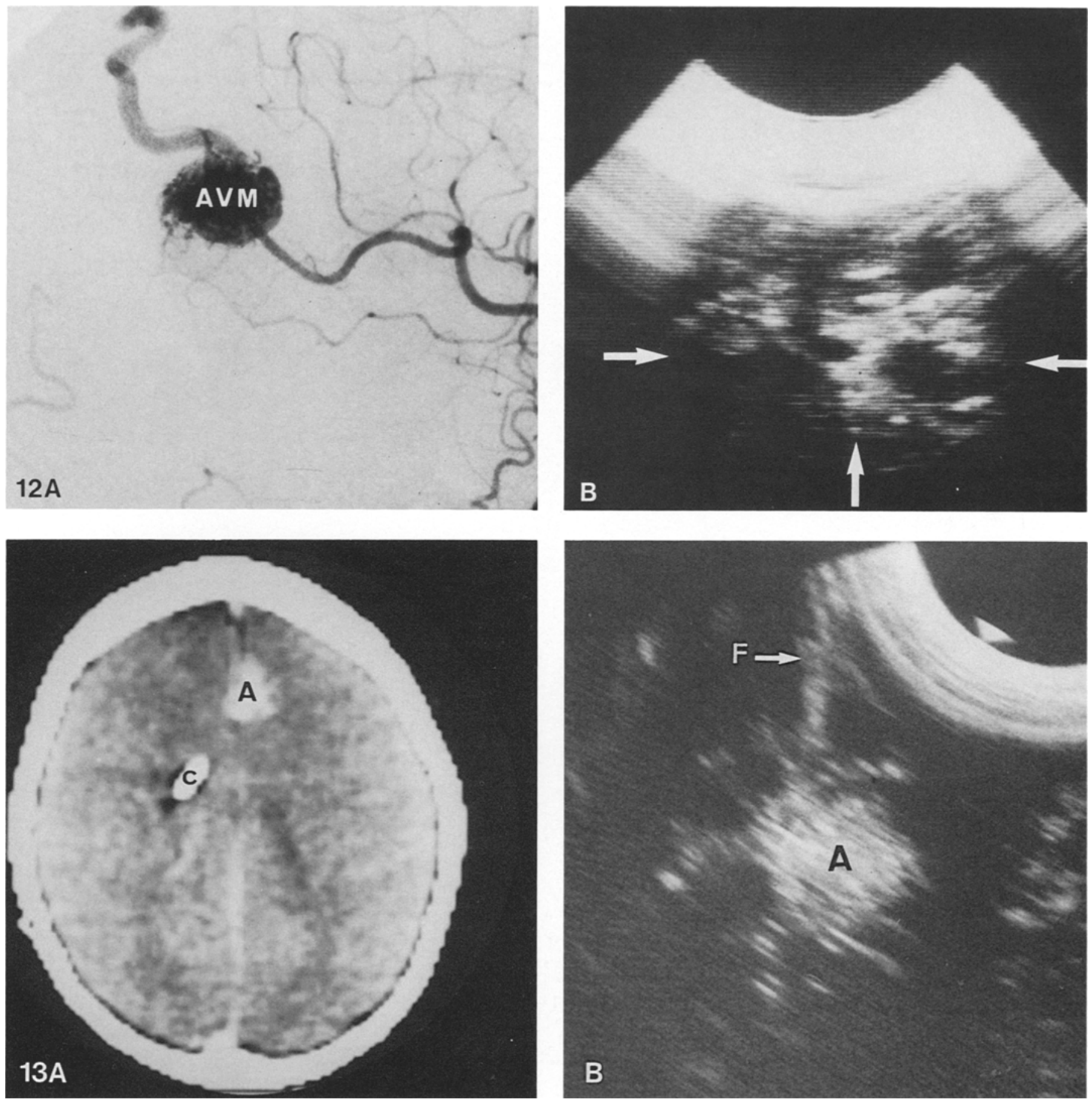

Fig. 12A. Angiogram demonstrating an arteriovenous malformation (AVM) with feeding artery and draining vein. B. Ultrasound image of AVM (between arrows) showing a mixture of high and low echogenicity.

Fig. 13A. CT scan of of a thrombosed arteriovenous malformation (A) in a patient with a shunt catheter (c). B. Ultrasound image showing the malformation $(\mathrm{A})$ and the falx $(\mathrm{F})$.

small vessels comprising the AVM itself produce the highly echogenic areas. Thrombosed AVM's (Fig. 13) are uniformly hyperechogenic and are indistinguishable from brain tumors.

Aneurysms greater than 4-5 mm image well with ultrasound. Since the lumen contains flowing blood, it is hypoechogenic and the rim is hyperechogenic. Any thrombosed portion of an aneurysm is readily identified. Figure 14 shows a large aneurysm adjacent to the brainstem. Figure 15 demonstrates how ultrasound was extremely useful in localizing a small $(5 \mathrm{~mm})$ mycotic aneurysm that was buried in a sulcus and was not at all distinguishable on the surface of the brain. Once localized, this aneurysm was easily excised. 

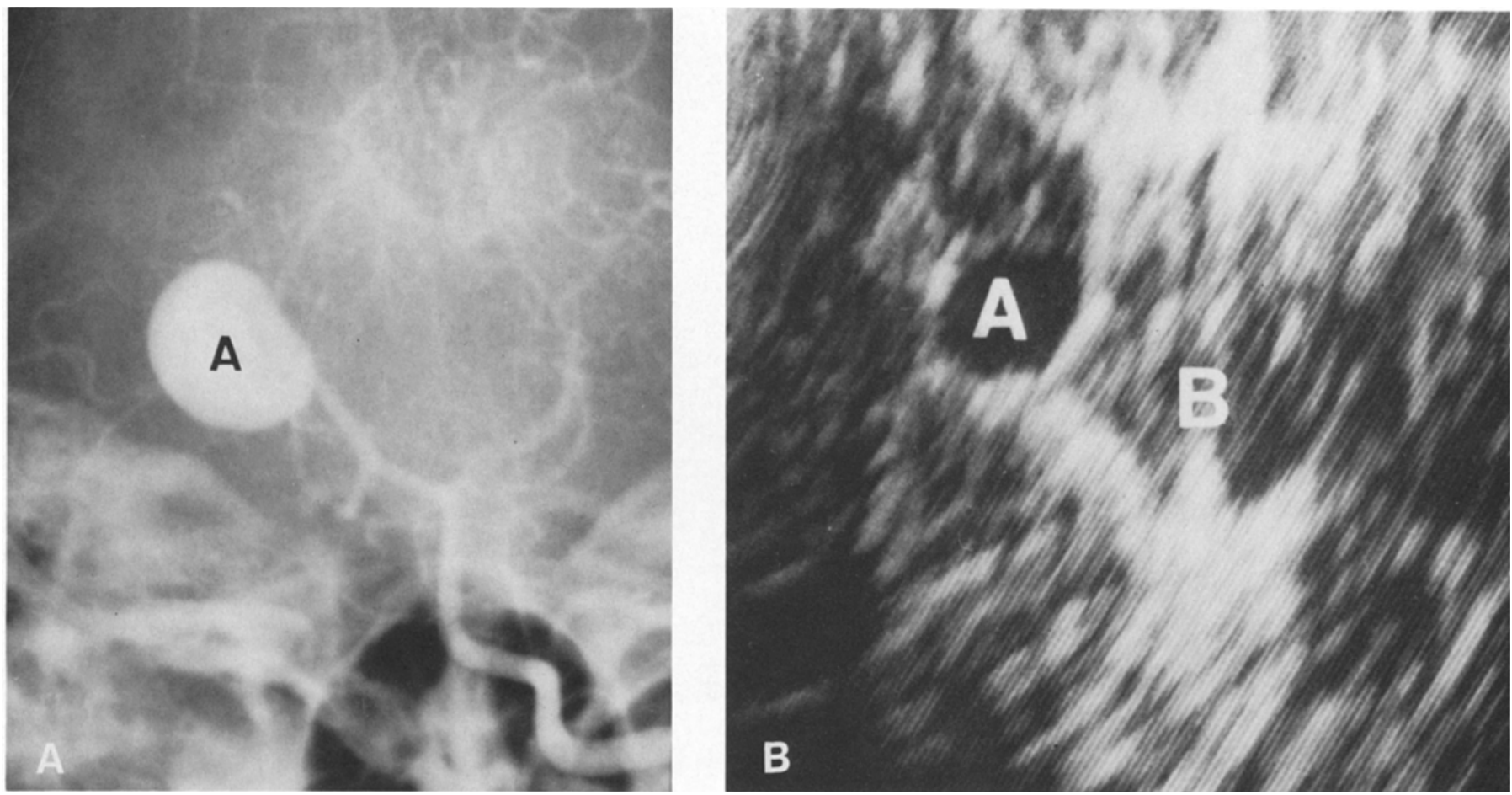

Fig. 14A. Angiogram showing a $1.5-\mathrm{cm}$ aneurysm of the posterior cerebral artery (A). B. Ultrasound images the aneurysm (A) as very low echogenicity and the brainstem (B) as moderately low echogenicity.

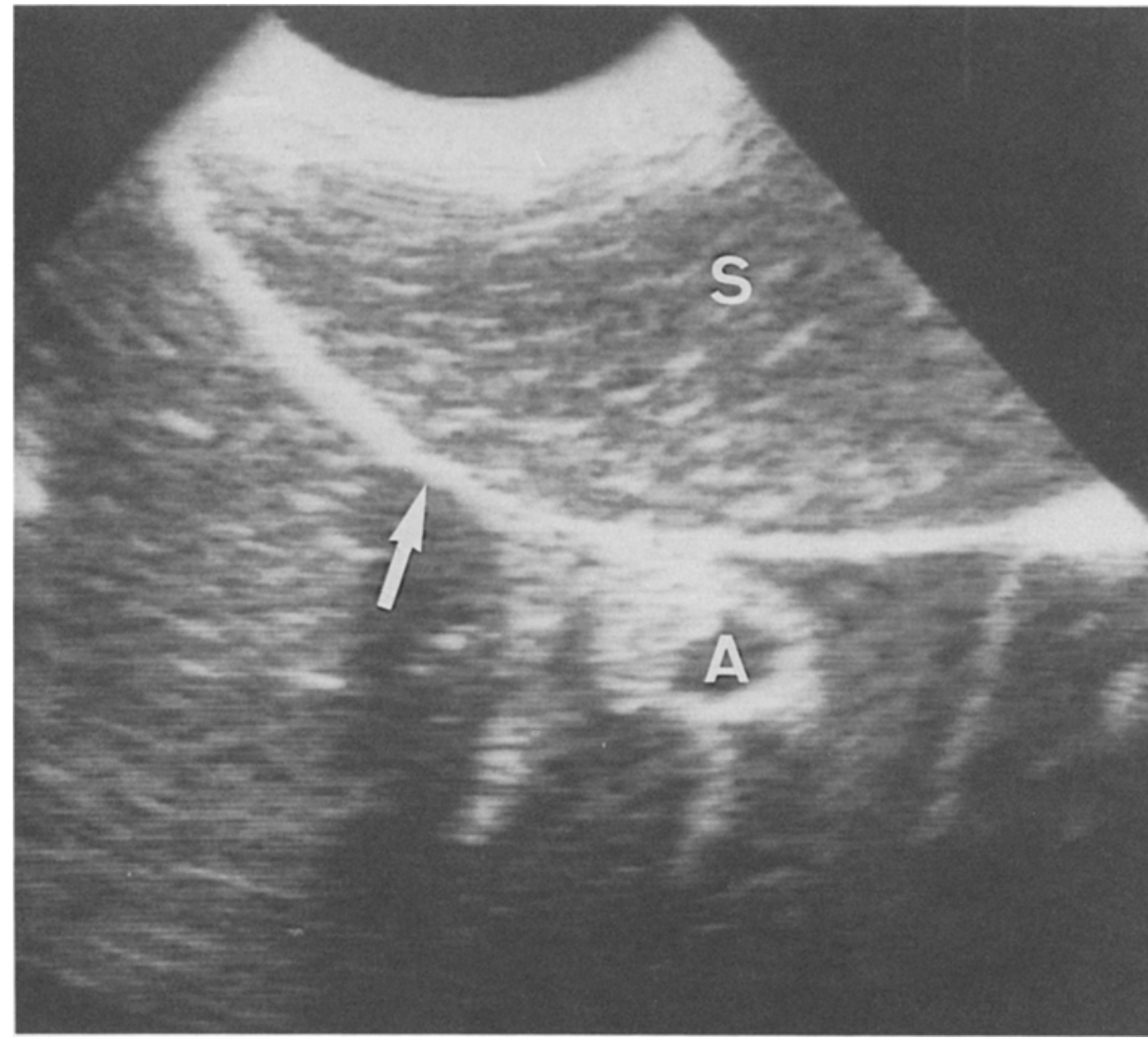

Fig. 15. Ultrasound image of a 5-mm mycotic aneurysm $(A)$. The aneurysm has a hypoechoic center and a hyperechoic rim, and lies immediately beneath the brain surface (arrow). Saline (S) in a rubber glove is placed between the transducer and the brain. 

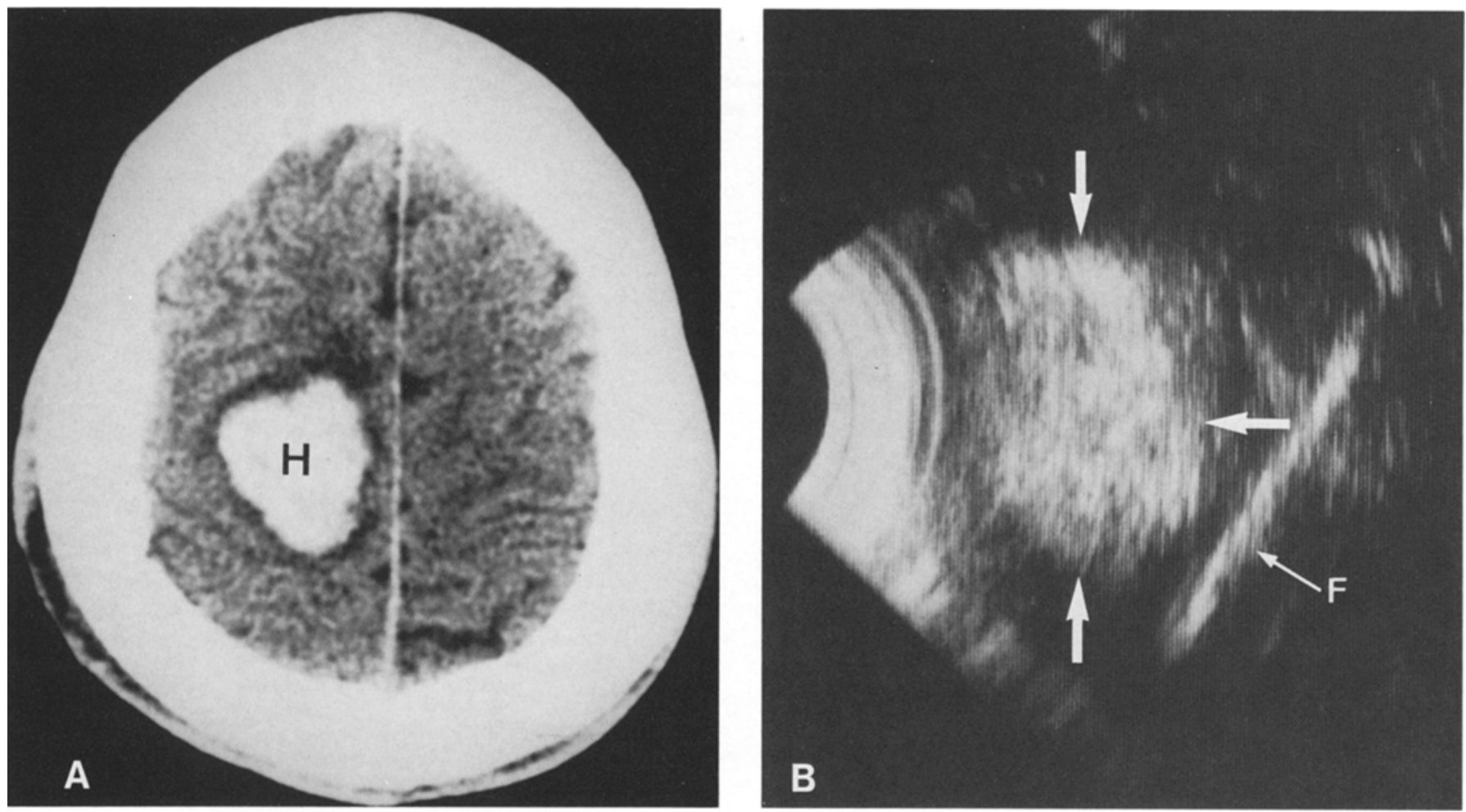

Fig. 16A. CT scan showing an intracerebral hematoma $(\mathrm{H})$. B. Ultrasound image of hematoma (between arrows) and falx $(\mathrm{F})$.
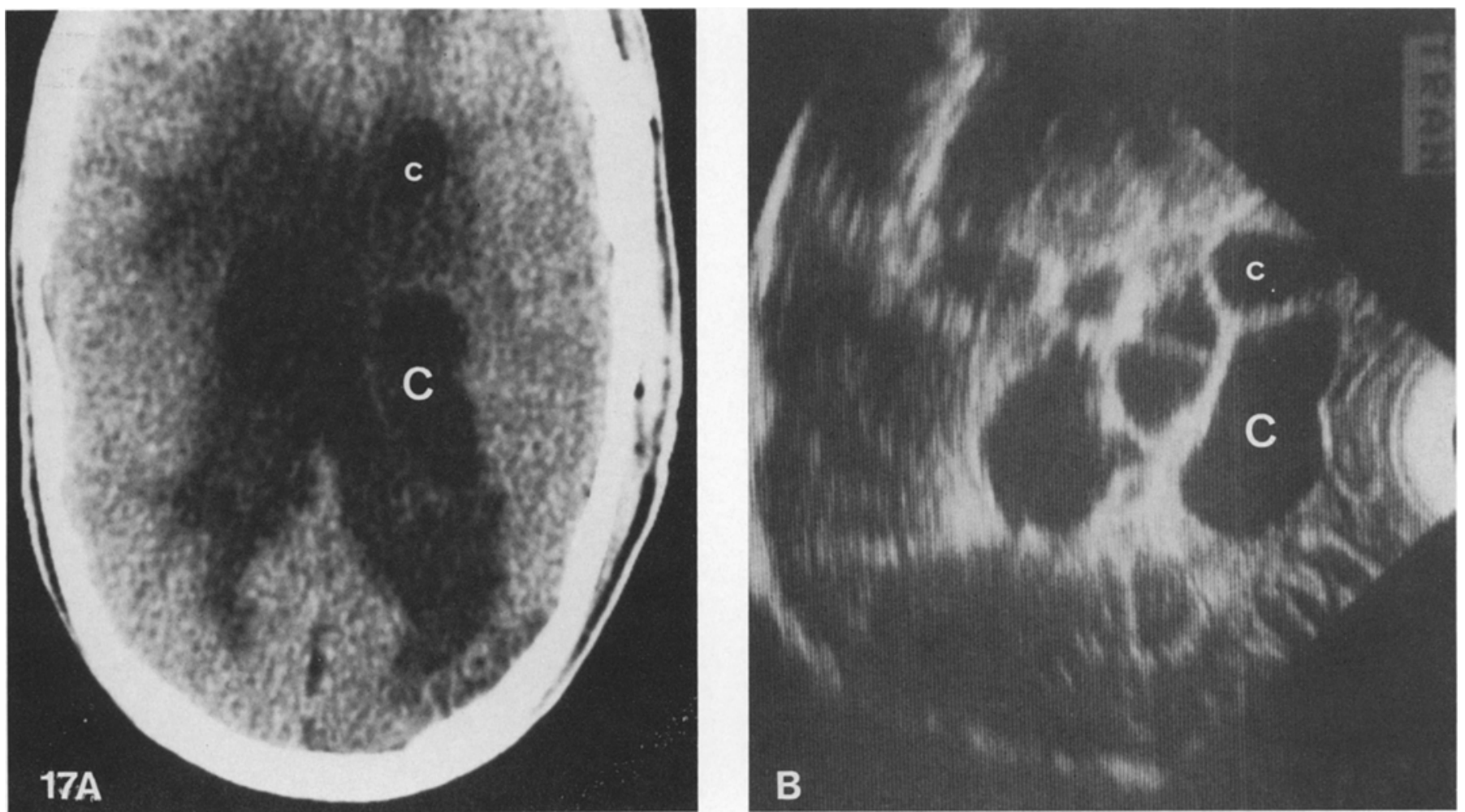

Fig. 17A. CT scan demonstrating hydrocephalus with multiple cystic components (C). B. Ultrasound shows the cysts (C) and septae. 

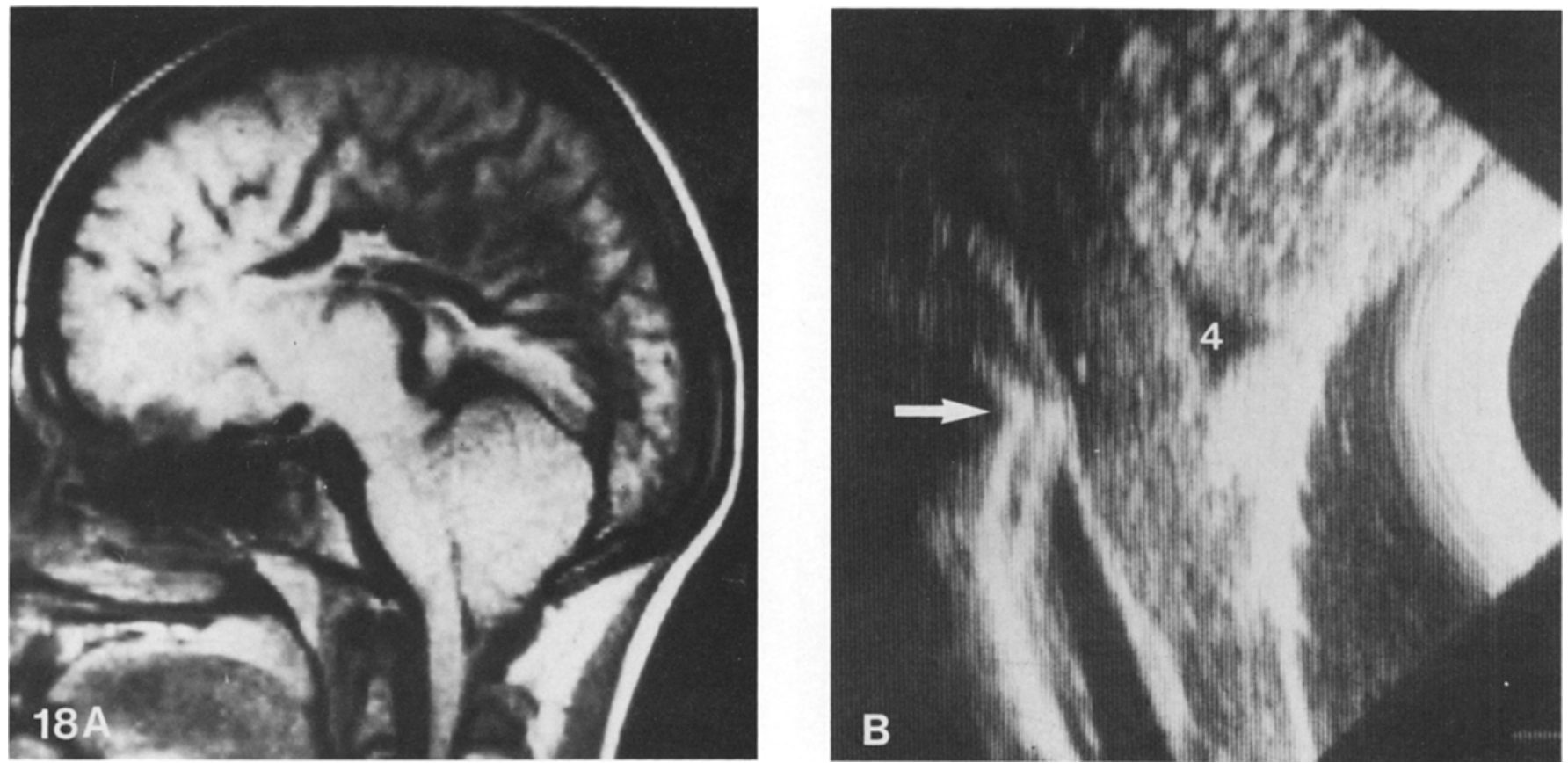

Fig. 18A. Magnetic resonance image scan of patient with Arnold-Chiari malformation. B. Ultrasound image of posterior fossa showing fourth ventricle (4) nearly below the foramen magnum (arrow).

\section{Hematomas}

Intracerebral hematomas, whether recent or up to a few days old, image as hyperechogenic masses. Figure 16 demonstrates a 2-day-old hematoma imaged intraoperatively. As mentioned above, hematomas occurring during surgery as a result of needle biopsy may be diagnosed and treated immediately. We have demonstrated in an animal model that an actively forming hematoma is hypoechogenic, but becomes hyperechoic within 30 seconds of formation [10]. This is true whether the blood is clotted or remains unclotted. After approximately a week to 10 days, clot breakdown and red cell destruction tend to make the hematoma appear more and more hypoechoic until it eventually becomes generally free of echoes.

\section{Structural Abnormalities}

Many anatomic abnormalities, whether congenital or acquired, image well with ultrasound. Virtually any variation of the ventricular system, including the fourth ventricle, can be imaged with ultrasound. This can be helpful when there are multiple septae within the ventricles during shunting procedures (Fig. 17).

Ultrasound imaging is particularly helpful during the surgical treatment of the Arnold-Chiari malformation since the size and location of the fourth ventricle can be imaged as well as any cyst or syrinx within the medulla or spinal cord (Fig. 18).

\section{Résumé}

L'emploi de l'échographie temps réel au cours des interventions neurochirurgicales cérébrales est décrit. Cet examen s'est montré extrêmement utile pour localiser un large éventail de lésions cérébrales superficielles ou profondes ainsi que pur pratiquer une biopsie aspiration de lésions spécifiques. La localisation précise des lésions grâce à l'image échographique diminue la durée de l'intervention et augmente la sécurité de l'acte opératoire.

Toutes les lésions tumorales primitives ou métastatiques du cerveau sont bien mises en évidence; le glioma à son début est mieux détecté par l'échographie que par la tomodensitométrie. Les abcès se manifestent par des images particulières et peuvent être évacués par aspiration; les hématomes se traduisent également par des images bien définies. De nombreuses lésions vasculaires: anévrysmes et malformations artério-veineuses peuvent être décelées et localisées. Des anomalies structurales comme L'hydrocéphalie et la malformation d'Arnold-Chiari peuvent être délimitées.

\section{Resumen}

Se describe el uso intraoperatorio de ultrasonido de tiempo real en el curso de procedimientos neuroquirúrgicos intracraneanos. Esta técnica ha probado ser extremadamente útil para la localización de una amplia variedad de lesiones cerebrales profundas y superficiales y para la biopsia o aspiración con aguja de lesiones seleccionadas. La precisión en la localización que provee la ultrasonografía acorta el tiempo operatorio e incrementa la seguridad del paciente.

Todo tipo de tumor primario o metastásico del cerebro ha sido bien delineado y los gliomas de bajo grado con frecuencia aparecen mejor definidos mediante el ultrasonido que con la escanografía computadorizada. Los abscesos pueden ser delineados y aspirados, y los hematomas son fácilmente delimitados. Una variedad de lesiones vasculares, incluyendo aneurismas y malformaciones arteriovenosas, pueden ser localizadas y bien definidas. Anormalidades estructurales tales 
como hidrocéfalo o la malformación de Arnold-Chiari también pueden ser bien delineadas.

\section{References}

1. French, L.A., Wild, J.J., Neal, D.: The experimental application of ultrasonics to the localization of brain tumors. Preliminary report. J. Neurosurg. 8:198, 1951

2. Donn, S.M., Goldstein, G.W., Silver, T.W.: Real-time ultrasonography. Its use in the evaluation of neonatal intracranial hemorrhage and posthemorrhagic hydrocephalus. Am. J. Dis. Child. 135:319, 1981

3. Chandler, W.F., Knake, J.E., McGillicuddy, J.E., Lillehei, K.O., Silver, T.M.: Intraoperative use of real-time ultrasonography in neurosurgery. J. Neurosurg, 57:157, 1982

4. Koivukangus, J.: Ultrasound imaging in operative neurosurgery.
Acta Univ. Ouluensis (Series D) 115:1, 1984

5. Masuzawa, H.: Intraoperative ultrasonography of the brain. Jpn. J. Med. Ultrasonics 7:277, 1980

6. Rubin, J.M., Mirfakhraee, M., Duda, E.E., Dohrmann, G.J., Brown, F.: Intraoperative ultrasound examination of the brain. Radiology 137:831, 1980

7. Voorhies, R.M., Patterson, R.H.: Preliminary experience with intraoperative ultrasonographic localization of brain tumors. Radiol. Nucl. Med. 10:8, 1980

8. Chandler, W.F., Knake, J.E.: Intraoperative use of ultrasound in neurosurgery. Clin. Neurosurg. 32:550, 1984

9. Rubin, J.M., Dohrmann, G.J.: Intraoperative neurosurgical ultrasound in the localization and characterization of intracranial masses. Radiology 148:519, 1983

10. Lillehei, K.O., Chandler, W.F., Knake, J.E.: Real-time ultrasound characteristics of the acute intracerebral hemorrhage as studied in the canine model. Neurosurgery 14:48, 1984 